\title{
O JORNAL ESCOLAR "O ESTUDANTE ORLEANENSE": UM OLHAR SOBRE AS MULHERES E A MATERNIDADE A PARTIR DAS CONTRIBUIÇÕES DE SIMONE DE BEAUVOIR (1949 - 1973)
}

\author{
Cintia Gonçalves Martins (Mestrado em Educação - PPGE/UNESC) ${ }^{1}$ \\ cintiamartins@unesc.net \\ Prof $^{a}$ Dra. Giani Rabelo (Orientadora) ${ }^{2}$ \\ gra@unesc.net
}

\section{RESUMO}

Esse trabalho busca apresentar uma investigação, em andamento, que tem o Jornal Escolar "O Estudante Orleanense" como objeto. O referido jornal escolar foi produzido pelas/os estudantes e professoras/os da Escola de Educação Básica Costa Carneiro, localizada no município de Orleans (SC), entre os anos de 1949 a 1973. À época o educandário tinha a nomenclatura de Grupo Escolar Costa Carneiro. O Jornal Escolar constitui-se em um artefato pedagógico que esteve fortemente presente nos educandários catarinenses durante o século XX e que, atualmente, está salvaguardado nos acervos documentais de algumas escolas. O objetivo central do estudo é compreender e problematizar, através de uma pesquisa documental com análise de conteúdo, as representações difundidas sobre as mulheres e maternidade nos referidos impressos. Ao todo foram encontrados 57 Jornais Escolares que estão disponibilizados no Centro de Memória da Educação do Sul de Santa Catarina (CEMESSC), no formato virtual. A análise será feita à luz de algumas das reflexões apresentadas na obra $O$ Segundo Sexo, volume um (1) "Fatos e Mitos" e o volume dois (2) "A Experiência Vivida" da escritora francesa Simone de Beauvoir (1949).

Palavras Chaves: Mulher/mulheres. Maternidade. Jornal Escolar.

\section{INTRODUÇÃO:}

Os impressos Escolares, neste caso os jornais escolares, foram documentos produzidos pelas/os educandas/os, a partir de práticas escriturais que levaram a produção de um suporte material que contribuiu para modificar a cultura escolar dos estabelecimentos de ensino brasileiros. No estado de Santa Catarina essa prática foi incorporada nos educandários nos primórdios do século XX.

$\mathrm{O}$ interesse em trabalhar com os Jornais Escolares surgiu quando encontramos alguns exemplares nos acervos das escolas públicas estaduais do extremo Sul

\footnotetext{
${ }^{1}$ Graduada em História - Bacharel e licenciatura, pela Universidade do Extremo Sul Catarinense UNESC. Mestranda do Programa de Pós Graduação - Mestrado em Educação da UNESC. Bolsista integral PROSUP/CAPES - UNESC. Aluna do Curso de Especialização em Gênero e Diversidade na Escola da Universidade Federal de Santa Catarina - Modalidade Semi Presencial. Membro do Grupo de Pesquisa História e Memória da Educação GRUPEHME/UNESC.

${ }^{2}$ Doutora em Educação pela Universidade Federal do Rio Grande do Sul (2008). Professora titular da Universidade do Extremo Sul Catarinense - UNESC. Atua no Curso de Pedagogia e no Programa de Pós - Graduação em Educação - UNESC. No PPGE/UNESC ocupa a função de coordenadora adjunta. Líder do Grupo de Pesquisa História e Memória da Educação GRUPEHME/UNESC.
} 


\section{SEMINÁRIO DE PESQUISA EM CIÊNCIAS HUMANAS - SEPECH \\ Humanidades, Estado e desafios didático-científicos \\ Londrina, 27 a 29 de julho de 2016}

Catarinense, envolvidas no projeto Centro de Memória da Educação do Sul de Santa Catarina (CEMESSC) ${ }^{3}$.

Ao tomarmos conhecimento dos artefatos salvaguardados pelos educandários notamos um déficit em relação aos documentos produzidos pelas/os estudantes/os, ou seja, produções de alunas/os são muito raras nos acervos escolares, parece-nos que tais documentos são os primeiros a serem descartados.

Com o processo de implantação do CEMESSC nos deparamos com diversos documentos produzidos internamente e externamente nas escolas ${ }^{4}$ entre eles encontramos documentos das Associações Auxiliares da Escola (AAEs), chamando-nos especial atenção as atas e os jornais escolares produzidos pelas mesmas.

Entre as escolas participantes do projeto a EEB Costa Carneiro ${ }^{5}$, contém números elevados de exemplares de Jornais Escolares em relação às outras instituições escolares que fazem parte do CEMESSC. Ao todo foram encontrados 57 (cinquenta e sete) exemplares do Jornal Escolar "O Estudante Orleanense" acompanhado de uma livro Ata de reuniões datada de 1949 a 1972 que contém registros das atividades da associação como, por exemplo, as eleições da diretoria do Jornal Escolar como também os encaminhamentos que os participantes do Jornal Escolar deveriam realizar a fim de manter o órgão escolar em funcionamento.

Os Jornais Escolares configuram-se como importantes fontes de pesquisa para o campo da História da Educação, pois trazem vestígios da cultura escolar, tecidas nestes estabelecimentos durante um determinado período, que nos dão possibilidade de nos aproximarmos do cotidiano, das práticas e saberes dos estabelecimentos de ensino. Compreendemos o conceito de cultura escolar a partir das reflexões de Viñao-Frago (2002 p. 75 - 74). Para ele:

Cultura escolar, assim entendida, seria composto por um conjunto de teorias, ideias, princípios, normas, orientações, rituais, inércia, hábitos e práticas (formas de fazer e pensar, atitudes e comportamentos) sedimentadas ao longo do tempo como tradições, regularidades e regras definidas nenhum jogo não é posta em causa, e compartilhada pelos autores, dentro das instituições educacionais. (Tradução nossa)

Para o referido autor, não existe apenas uma cultura escolar que contemple a todos os educandários, mas culturas escolares múltiplas, cada instituição educacional é

\footnotetext{
${ }^{3}$ O projeto foi realizado pelo GRUPEHME, aprovado em 2009, pelo Conselho Nacional de Desenvolvimento Científico e Tecnológico (CNPQ) tem o intuito de criar uma cultura voltada para a preservação da memória dos educandários do Sul do estado de Santa Catarina. O CEMESSC é composto por um acervo digital que contêm documentos textuais, iconográficos, objetos digitalizados ou fotografados que fazem parte dos acervos das escolas públicas de Santa Catarina. Participaram do projeto as microrregiões AMREC, AMESC e AMUREL, que formam o sul de Santa Catarina. Entre as microrregiões participantes foram escolhidas 27 escolas estaduais mais antigas, entre as três microrregiões.

${ }^{4}$ Entre a documentação salvaguardada, estão às atas de reuniões, fotografias, livros didáticos, documentos da Associação de pais e professores, documentos referentes a Associações Auxiliares da Escola, sendo elas: Liga Pró Língua Nacional; Caixa Escolar; Cooperativa Escolar, Clube Agrícola; Pelotão de Saúde, Biblioteca Escolar; Jornais Escolares, Clube de Leitura, Liga da Bondade, Círculo de Pais e Professores, Orfeão Escolar, Museus Escolares e Centros de Interesses.

${ }^{5}$ O Grupo Escolar Costa Carneiro, desde 2002 é denominado de Escola de Educação Básica CostaCarneiro. A escola fica localizada na Rua Aristiano Ramos 205, Centro, Orleans - SC.
} 


\section{SEMINÁRIO DE PESQUISA EM CIÊNCIAS HUMANAS - SEPECH \\ Humanidades, Estado e desafios didático-científicos \\ Londrina, 27 a 29 de julho de 2016}

composta por práticas e fazeres diversos, os estabelecimentos têm suas especificidades de metodologias e processos educacionais, pois o ambiente escolar é composto por sujeitos diversos. Nesse sentido, faz-se necessário compreendermos brevemente $o$ contexto histórico de implantação da AAEs responsáveis pela organização do Jornal Escolar "O Estudante Orleanense", no contexto catarinense.

\section{AS ASSOCIAÇÕES AUXILIARES DA ESCOLA E O JORNAL ESCOLAR: O CONTEXTO HISTÓRICO DE IMPLANTAÇÃO NO ESTADO DE SANTA CATARINA}

A inserção dos Jornais Escolares nas escolas públicas catarinenses se deu em um processo de mobilização nacional dos governos e intelectuais republicanos na busca de uma identidade nacional e de novas práticas educacionais capaz de civilizar, higienizar e disciplinar a população para uma nova sociedade moderna e homogênea. A partir da proclamação da República, em 15 de Novembro de 1889, inicia-se um longo processo de reformas no sistema educacional brasileiro, fortalecendo-se nos anos de 1930 a 1945 , no governo do presidente Getúlio Vargas.

Foram vários os investimentos no sistema educacional brasileiro, iniciando na construção de Grupos Escolares, aquisição de materiais pedagógicos, formação de educadores/as e a criação de inúmeras leis e decretos que vislumbravam modernas metodologias educacionais, com o intuito de formar sujeitos com forte identidade nacional e patriótica, mão de obra trabalhadora para a construção da nova nação e crianças com valores morais, cívicos e éticos baseado em princípios cristão-católicos. $\mathrm{O}$ principal objetivo era "despertar os sentimentos de amor e dever à família, à sociedade e, principalmente, à pátria.” (BENCOSTTA, 2005, p.75.)

As novas metodologias educativas que deveriam ser postas em práticas nos educandários estavam alicerçadas nos princípios dos intelectuais republicanos brasileiros, no movimento denominado Escola Nova, que tinha, como perspectiva educacional, colocar-se em oposição aos métodos de ensino da escola tradicional. A proposta da Escola Nova estava baseada no modelo educacional Norte Americano dos professores John Dewey e Willian Kilpatrick.

Entre as novas medidas educativas, estava a criação das Associações Auxiliares da Escola, que em Santa Catarina foram regulamentadas pelo decreto Estadual n. 2.991 de 28 de abril de 1944, publicado no Diário Oficial do Estado de Santa Catarina em 09 de maio de 1944, no governo do interventor federal Nereu Ramos (1937-1945). Tratase, portanto, da legislação que regulamenta oficialmente a aplicação das AAE. Segundo Petry (2013), as AAEs são uma espécie de auxiliadora das atividades escolares no que diz respeito à socialização, moralização e civilização dos educandos, tendo a função de aproximar a família e a escola. .

O jornal escolar, produzido no interior das associações, contém registrado o cotidiano das alunas/os, como acontecimentos sobre suas vidas, seus pensamentos e modo de agir diante de determinadas situações, a história de sua região e da escola, as datas festivas e comemorações escolares, lições de moral e civismo, orações, suas produções artísticas entre outros aspectos da vida na comunidade escolar. Esses artefatos são manuscritos estudantis que registram o cotidiano da vida escolar na 


\section{SEMINÁRIO DE PESQUISA EM CIÊNCIAS HUMANAS - SEPECH \\ Humanidades, Estado e desafios didático-científicos \\ Londrina, 27 a 29 de julho de 2016}

perspectiva dos educandos/as, contribuindo para a produção de culturas dentro das instituições educativas.

Entretanto, é fundamental salientar que as/os alunas/os não são os únicos sujeitos envolvidos na produção dos impressos escolares. Ao ler e analisar o Jornal Escolar "O Estudante Orleanense" como também os registros das reuniões da associação, observamos as manifestações de professoras/es, diretoras/es do Grupo Escolar Costa Carneiro, pessoas da comunidade, religiosos e leigos, influenciando na elaboração do impresso.

Desse modo, nos registros escriturais do Jornal Escolar, deparamos com vestígios da cultura escolar dos estabelecimentos de ensino, como também com concepções sobre determinados assuntos daquelas/es que os produziram ou das/os que contribuíram para a sua construção de forma direta ou indireta. Nesse sentindo, buscamos compreender a representações difundidas sobre as mulheres e maternidade no Jornal Escolar "O Estudante Orleananse" e para isso se faz necessário uma breve discussão sobre o conceito de gênero.

\section{GÊNERO NO JORNAL ESCOLAR “O ESTUDANTE ORLEANENSE"}

Nos exemplares do Jornal "O Estudante Orleanense" encontram-se vestígios da cultura escolar permeadas por representações de gênero que estão inseridos nos textos e imagens que compõem os mesmos, dando visibilidade aos estereótipos de feminino e masculino que reforçam a desigualdade de gênero, dentro do contexto histórico no qual formam produzidos. Utilizamo-nos da compreensão conceitual de gênero definido pela historiadora Joan Scott. Nas palavras da autora gênero é:

O núcleo da definição repousa numa conexão integral entre duas proposições: (1) o gênero é um elemento constitutivo de relações sociais baseadas nas diferenças percebidas entre os sexos e (2) o gênero é uma forma primária de dar significado às relações de poder. As mudanças na organização das relações sociais correspondem sempre a mudanças nas representações do poder, mas a mudanças não é unidirecional. (SCOTT, 1995, p. 86)

Para a historiadora,as relações de gênero são construídas pelas relações históricas e sociais, sendo elas baseadas nas diferenças entre o sexo feminino e masculino, constituídas dentro das relações de poder. Desta maneira, gênero se contrapõe a ideia de que as desigualdades entre o masculino e feminino são dadas por determinantes biológicos que são naturalizados ao longo do processo histórico, problematizando tais determinismos, com o objetivo de (des)naturalizá-los.

A categoria de gênero constitui-se a partir de uma construção histórica e social do que definimos por masculino e feminino, bem como por seus atributos, que ultrapassam o que é para uma esfera construída historicamente, culturalmentee socialmente, ou seja, o que naturalizamos como características sociais do feminino e masculino são construções e não dados da natureza humana. Nessa perspectiva, muitas das características atribuídas às mulheres ao longo do processo histórico da sociedade ocidental tornaram-se naturalizadas a partir do discurso biológico que inferioriza as 


\section{SEMINÁRIO DE PESQUISA EM CIÊNCIAS HUMANAS - SEPECH \\ Humanidades, Estado e desafios didático-científicos \\ Londrina, 27 a 29 de julho de 2016}

mulheres perante os homens, contribuindo para a opressão e a violência do sexo feminino.

Em vista disso, surgiram as primeiras indagações acerca do Jornal Escolar " $\mathrm{O}$ Estudante Orleanense": Quais representações de feminino e masculino permeiam os impressos escolares? Que prescrições de masculino e feminino foram disseminadas nos Jornais Escolares? Como se deu a participação de meninos e meninas na elaboração dos Jornais Escolares? Quais os temas veiculados nos jornais que eram atribuídos às meninas/mulheres?

Ao realizarmos uma breve análise de conteúdo do Jornal Escolar, tomando como referência as questões já mencionadas, constatamos que a desigualdade de gênero está presente no Jornal Escolar "O Estudante Orleananse", indo desde a composição da diretoria e da equipe de reportares até a escolha e redação dos textos para compor os vários números do periódico. Enfim, é possível afirmar que a desigualdade de gênero atravessa o referido impresso escolar.

Entretanto, a questão que mais salientou-se foi a representação de mulher/mulheres difundido nas páginas do impresso escolar. Inicialmente nota-se uma invisibilidade do feminino nos escritos do Jornal, isto é, não encontramos noticias, personalidades históricas. As mulheres aparecem nos textos do Jornal Escolar "O Estudante Orleanense" apenas vinculadas às questões relacionadas à maternidade. Elas são descritas ou representadas somente no mês de Maio, data que comemora-se o dia das mães, no Brasil desde a década de 1930. Tal representação é carregada de estereótipo, de como ser mãe, o que é ser mãe, como uma mãe deve comportar-se socialmente etc.

Diante desse quadro, buscamos os escritos da filósofa existencialista Simone de Beauvoir sobre a condição feminina na obra O Segundo Sexo, volume um (1) "Fatos e Mitos" e o volume dois (2) "A Experiência Vivida", a fim de compreender a condição feminina atrelada ao destino materno, difundido nas páginas do Jornal Escolar "O Estudante Orleanense".

\section{O JORNAL ESCOLAR E AS REPRESENTAÇÕES DE MULHER/MULHERES E MATERNIDADE À LUZ DAS CONTRIBUIÇÕES DE SIMONE DE BEAUVOIR}

\footnotetext{
"Ninguém nasce mulher: torna-se mulher. Nenhum destino biológico, psíquico, econômico define a forma que a fêmea humana assume na sociedade; é o conjunto da civilização que elabora esse produto intermediário entre o macho e o castrado que qualificam de feminino." (BEAUVOIR, 2009, p. 361)
}

Iniciamos utilizando-nos da emblemática frase de Simone de Beauvoir sobre a construção da mulher na sociedade, compreendendo que "é preciso aprender a ser mulher, uma vez que o feminino não é dado pela biologia, ou mais simplesmente pela anatomia, e sim construído pela sociedade" (SAFFIOTI, 1999, p.160). Beauvoir é uma das primeiras a questionar, já no final dos anos de 1940 na França, a condição das quais as mulheres estavam submetidas no meio social, afirmando que não são as características biológicas, psíquicas ou econômicas que a define como a mulher e sim o 


\section{SEMINÁRIO DE PESQUISA EM CIÊNCIAS HUMANAS - SEPECH \\ Humanidades, Estado e desafios didático-científicos \\ Londrina, 27 a 29 de julho de 2016}

meio social que ela está inserida, questionando os argumentos que naturalizam os atributos ditos femininos. Segundo a autora: Beauvoir (2009, p. 70)

É, portanto, à luz de um contexto ontológico, econômico, social e psicológico que teremos de esclarecer os dados da biologia. A sujeição da mulher à espécie, os limites de suas capacidades individuais são fatos de extrema importância; o corpo da mulher é um dos elementos essenciais da sua situação que ela ocupa neste mundo. Mas, não é ele tampouco que basta para a definir. Ele só tem realidade vivida enquanto assumido pela consciência através das ações e no seio de uma sociedade; a biologia não basta para fornecer uma resposta à pergunta que nos preocupa: por que a mulher é o Outro? Trata-se de saber o que a humanidade fez da fêmea humana.(BEAUVOIR, 2009, p. 70).

Com tais questionamentos sobre a fêmea humana é que Simone torna-se uma das personagens mais referenciadas na história do Feminismo e da luta das mulheres, assim sendo faz-se necessária compreendemos brevemente sua trajetória.

Simone de Beuavoir nasceu na cidade de Paris-França, no dia 9 de janeiro de 1908 e faleceu no dia 14 de abril de 1986, aos 78 anos de idade. Criada em uma família francesa tradicional católica, na qual seu pai era advogado e sua mãe pertencente à burguesia francesa, era a primogênita de duas irmãs. Sua família entrou em falência com a crise econômica que atingia a Europa a partir da Primeira Guerra Mundial (19141919). Simoni estudou no curso Désis de orientação católicas e sua formação acadêmica foi em filosofia, em 1929. (PASSOS, 1999). Professora, filósofa, escritora e integrante do movimento existencialista francês. Revelou sua crença no comprometimento do intelectual com o tempo no qual ela/ele vive, além de publicar livros filosóficos e ensaios se dedicou a registrar suas experiências em obras autobiográficas, que relatam as condições de seu tempo. Condições essas que inferiorizavam grupos a partir de discursos biológicos, entre eles, as mulheres que eram condicionadas ao seu corpo e às suas funções biológicas de procriação. Nesse Contexto, Simone escreve e publica o livro $O$ segundo Sexo -volume1 - Fatos e Mitos e o volume 2 - Experiências Vividasno final da década de 1940, na França, período, pós Segunda Guerra Mundial.

Nesta obra a autora não nega as diferenças biológicas entre homens e mulheres, entretanto ela questionava o discurso do determinismo biológico, ou seja, a mulher não poderia ser colocada em uma condição inferior ao homem por questões biológicas, pois, na visão dela não se poderiam ignorar os aspectos históricos e sociais, ou seja, a desigualdade entre o feminino e masculino não era algo resultante dos aspectos biológicos. De Acordo com Passos (1999, p. 44)

Apesar de só ter oficializado sua vinculação à política feminista 23 anos após a publicação do clássico O Segundo Sexo, de 1949, em toda a sua obra a questão feminina acha-se de alguma forma presente. $\mathrm{Na}$ Força da Idade, ela demonstra que a educação que recebeu estava em conformidade com a mulher que ela devia ser. $\mathrm{O}$ fato de preocupar-se com a política e ter ambições vinha de sua teimosia. 


\section{SEMINÁRIO DE PESQUISA EM CIÊNCIAS HUMANAS - SEPECH \\ Humanidades, Estado e desafios didático-científicos \\ Londrina, 27 a 29 de julho de 2016}

Simone não utilizou da categoria gênero, esse conceito começará a ser empregado pelas estudiosas e feministas na década de 1960, entretanto, suas obras são precursoras para a compreensão do conceito. A autora contribui de forma significativa para o entendimento a respeito da condição das mulheres na sociedade e faz uma forte crítica ao patriarcado, rebatendo a ideia de que o biológico não pode determinar a condição de inferioridade das mulheres na sociedade. Para Simone "o corpo é um modo de tornar-se", entretanto, o fato de "não se nascer mulher", mas "tornar-se mulher" não significa que isto se dê de forma linear, usando uma liberdade desligada da cultura. "Ao contrário, nascemos corpo e só depois nos tornamos gênero.” (PASSOS, 1999, p. 49)

Portanto, ao analisamos as representações de mulher/mulheres nos impressos escolares da EEB Costa Carneiro, detectamos que a função social da mulher disseminada no Jornal Escolar está inter-relacionada à maternidade, ou seja, as publicações veiculadas não alocam a mulher fora do seu destino biológico, colaborando para a construção da ditadura da maternidade, da qual aprisiona as mulheres ao papel de mãe e, consequentemente, ao de esposas.

Simone de Beauvoir, na obra $O$ Segundo Sexo, mostra-se como uma das vozes mais libertárias desse tipo de pensamento, buscando com argumentos fundamentados em diversas áreas do conhecimento, distanciar a mulher do seu destino biológico, logo um dos pontos defendido por ela era se posicionar contra a maternidade. (CORDEIRO, 2013)

Como exemplo da difusão da representação da mulher atrelada à maternindade, escolhemos 01 (um) texto do Jornal Escolar "O Estudante Orleananse", publicado em Maio de 1957. Ao todo, entre os cinquenta e sete (57) exemplares do jornal foram identificados quinze (15) impressos que abordam a figura feminina relacionada à maternidade, contudo não caberia nesse ensaio apresentar e problematizar todos os escritos, assim, optamos pelo texto que segue.

No mês de Maio de 1957, data simbólica de comemoração ao dia das mães, as/os redatoras/es do Jornal Escolar "O Estudante Orleanense" 6 publicam um texto em homenagem ao Dia das Mães.

\footnotetext{
${ }^{6} \mathrm{O}$ jornal Escolar "Estudante Orlenanse" sofreu variações quanto à sua denominação. Aparecem nos exemplares analisados as seguintes nomenclaturas: "O Estudante", "O Estudante Orleanês", entretanto a maioria dos Jornais consta a nomenclatura o "O Estudante Orleanense".
} 


\section{SEMINÁRIO DE PESQUISA EM CIÊNCIAS HUMANAS - SEPECH \\ Humanidades, Estado e desafios didático-científicos \\ Londrina, 27 a 29 de julho de 2016}

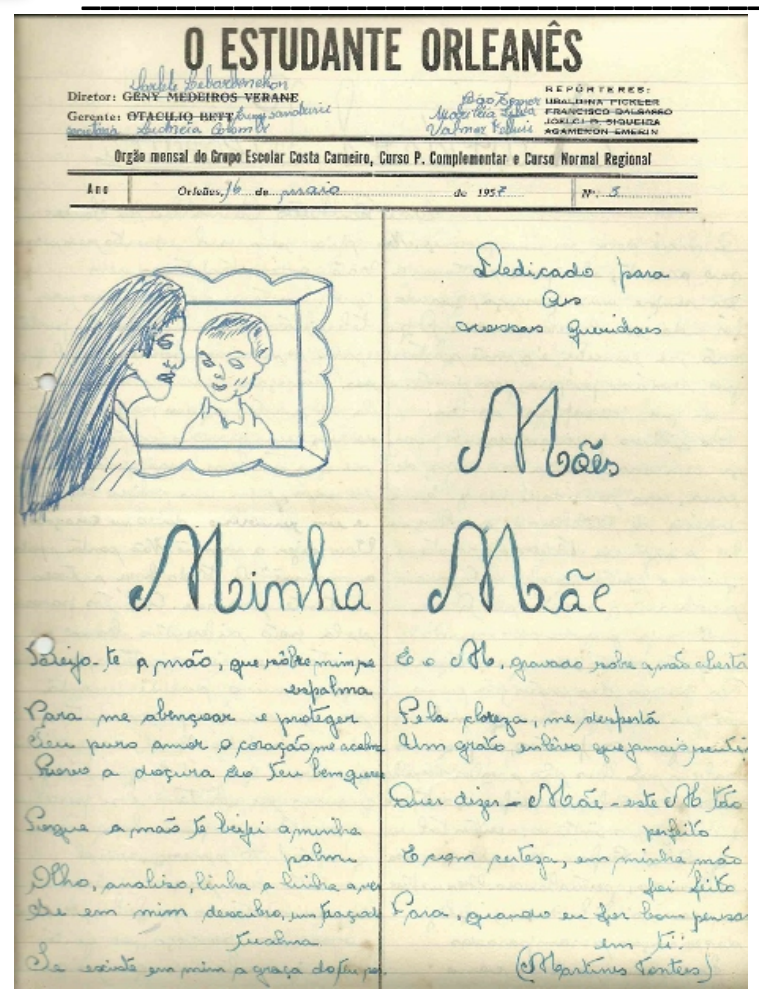

Figura 1: Jornal Escolar O Estudante Orleanense (Maio de 1957)

Fonte: Centro de Memória da Educação do Sul de Santa Catarina - CEMESSC - Acervo da EEB Costa Carneiro

O texto não é uma produção própria das/os alunas/os e sim uma cópia de um texto original de autoria de Martins Fontes. Os versos que compõem a poesia retratam um amor incondicional pela figura materna, colocando-a como uma personagem pura e amorosa na qual as/os filhas/os devem se espelhar, evidenciando que as mulheres quando ao tornarem-se mães, passam a se constituir como sujeitos importantes para o meio social.

De acordo com Cordeiro (2013), o filósofo iluminista Jean-Jacques Rousseau teve um papel fundamental para cativar as mulheres e fazer "aflorar" o seu instinto maternal. Em suas obras o filósofo enaltece as mulheres por serem mães, pois somente elas poderiam procriar. Essa característica biológica foi muito explorada por aqueles que buscavam persuadir as mães a todo custo. Segundo Beauvoir (2009, p. 163) "Rousseau, que aqui se faz o interprete da burguesia, destina a mulher ao marido e à maternidade."

Ao analisamos o texto acima observamos como as ideias de Rousseau estão presentes na mensagem dirigida às mulheres no Dia das Mães, pois coloca o amor materno como algo biologicamente determinado, pondo a mulher que é mãe em uma posição privilegiada socialmente. Nessa perspectiva, a maternidade passou a ser associada ao divino. As mulheres que se tornam mães com a gestação, passam a ser vistas como um ser duplo, ou seja, mulher e mãe ao mesmo tempo, sendo revestido por uma aura de sacralidade que perpetua o mito do amor materno. Com o nascimento da criança a mãe devota sua vida totalmente às/aos filhas/os, negando-se como um sujeito.

Desse modo, ao longo da formação da sociedade, principalmente do modelo capitalista, ser mãe constitui-se por algo instintivo, essencial a todos os seres femininos. A mulher tornaria um ser completo quando seguisse vivenciar o ciclo considerado como 


\section{SEMINÁRIO DE PESQUISA EM CIÊNCIAS HUMANAS - SEPECH \\ Humanidades, Estado e desafios didático-científicos \\ Londrina, 27 a 29 de julho de 2016}

"natural", toda a fêmea humana deveria então crescer, casar, ter filhas/filhos e morrer. (CORDEIRO, 1999)

Contradizendo a esse argumento determinista, Simone aponta dois preconceitos sobre a maternidade, isto é, que a "realização da maternidade bastaria para satisfazer e tornar feliz a mulher e a de que todo filho encontraria felicidade segura nos braços maternos". (ALMEIDA, 1999, p. 153) A autora problematiza a maternidade, descrevendo como o ato da gravidez pode aniquilar as mulheres. Nas palavras de Beauvoir (2009, p. 662):

[...] a gravidez é principalmente um drama que se desenrola na mulher entre si e si; ela sente-o a um tempo como um enriquecimento e uma mutilação; o feto é uma parte de seu corpo e um parasita que a explora; ela o possui e é por ele possuída; ele resume todo o futuro e, carregando-o, ela sente-se ampla como o mundo; mas essa própria riqueza a aniquila: tem a impressão de não ser mais nada. Uma existência nova vai manifestar-se e justificar sua existência; disso ela se orgulha, mas sente-se também o joguete de forças obscuras, é sacudida, violentada.

A autora desconstrói o mito do amor materno como algo natural, problematizando o quanto a gravidez e a maternagem podem ser prejudiciais para as mulheres que pretendem tornarem-se mães. Simone retrata a partir de suas pesquisas, que nem todas as mulheres vivenciam o período materno igualmente, ou seja, não existe um padrão único para essa experiência, dependendo do tempo e espaço que as mesmas estão inseridas. Nota-se a partir deste e de outros textos publicados no Jornal Escolar "O Estudante Orleanense", a difusão da ideia de mãe amorosa, cuidadosa que abdica da vida pública em nome da vida privada, ocultando os pontos negativos da maternidade, ou melhor, tentando impedir que as mulheres reflitam sobre o fato de que a maternidade é uma escolha e não um destino.

\section{CONSIDERAÇÕES CONCLUSIVAS}

O Jornal Escolar "O Estudante Orleanense" foi redigido e publicado no Grupo Escolar Costa Carneiro durante, aproximadamente, três décadas. As/os educandas/os, que passaram pelos seus bancos escolares provavelmente tiveram acesso aos seus escritos e por sua vez, tais jornais contribuíram para a construção da cultura escolar do educandário. Como podemos perceber os textos e imagens publicadas no impresso " $\mathrm{O}$ Estudante Orleanense" contêm argumentos que naturalizam a maternidade como destino para as mulheres, contribuindo para a criação de um imaginário social que reforça a condição meramente biológica da mulher e sua vocação para a maternidade e maternagem.

Contrapondo-se a esse discurso biológico, Simone de Beauvoir contribui fundamentalmente para compreendermos a construção do modelo feminino em nossa sociedade ocidental permeada por aspectos sociais e históricos. A autora não nega a condição biológica da mulher, entretanto questiona o fato de que este argumento seja o único para defini-la como um sujeito. 


\section{SEMINÁRIO DE PESQUISA EM CIÊNCIAS HUMANAS - SEPECH \\ Humanidades, Estado e desafios didático-científicos \\ Londrina, 27 a 29 de julho de 2016}

Vivemos em uma sociedade em que a cultura machista permanece enraizada. Em pleno século XXI, não conseguimos superar a condição do determinismo biológico que marca profundamente a condição das mulheres no meio social. Resultado disso são as inúmeras formas de violências que as mulheres sofrem justificadas a partir do discurso biológico, como violência doméstica, violência simbólica,violência sexual e psicológica, além de receberem menores salários que os homens quando ocupam as mesmas funções. Desse modo, as obras de Simone Beauvoir são fundamentais para compreendermos nossa sociedade atual, bem como, para fundamentarmos a necessidade da luta por igualdade entre os gêneros masculinos e femininos, especialmente para a emancipação e libertação feminina na sociedade contemporânea, pois seu legado questiona o modelo estabelecido para as mulheres e dialoga com mulheres que não seguem padrões sociais, contribuindo para promover rupturas com o processo de naturalização da desigualdade entre homens e mulheres.

\section{REFERENCIAS:}

ALMEIDA, MarliseMíriam de Matos. Simone de Beauvoir: uma luz em nosso caminho. Cadernos de Pagu (12), "Simone de Beauvoir \& os Feminismos do Século XX”, CORREAA, Mariza (org.), Campinas: UNICAMP, Dezembro de 1999.

BEAUVOIR, Simone. O segundo sexo: volume único. Tradução Sérgio Milliet. 2. Ed. Rio de Janeiro: Nova Fronteira, 2009.

CORDEIRO, Mariana Sbaraini. Mãe - A Invenção da História.Seminário Internacional Fazendo Gênero 10 (Anais Eletrônicos), Florianópolis, 2013. ISSN 2179$510 \mathrm{X}$.

Disponível em:http:/www.fazendogenero.ufsc.br/10/resources/anais/20/1386710409 ARQUIVO MarianaSbarainiCordeiro.pdfAcesso em 07 de Jan. de 2016.

PASSOS, Elizete. O existencialismo e a condição feminina. In: BRITTO DA MOTTA, Alda; SARDENBERG, Cecília; GOMES, Márcia. Um diálogo com Simone de Beauvoir e outras falas. Salvador: NEIM/UFBA, 2000. P.39-48. Disponível em: http://www.neim.ufba.br/wp/wp-content/uploads/2013/11/simone.pdf Acesso em: $27 / 08 / 2015$

PETRY, Marilia Gabriela. Da recolha à exposição: a constituição de museus escolares em escolas públicas primárias de Santa Catarina (Brasil - 1911 a 1952). 2013. $224 \mathrm{f}$. Dissertação (Mestrado em educação) - Universidade do estado de Santa Catarina, Florianópolis.

SCOTT, Joan. Gênero: uma categoria útil de análise histórica. Educação e realidade. Porto Alegre, v. 20, 2, p. 71-99, jul/dez, 1995.

SAFFIOTI, Heleieth I B. Primórdios do conceito de gênero.Cadernos de Pagu (12), "Simone de Beauvoir \& os Feminismos do Século XX", CORRÊA, Mariza (org.), Campinas: UNICAMP, Dezembro de 1999. Disponível em: 


\section{SEMINÁRIO DE PESQUISA EM CIÊNCIAS HUMANAS - SEPECH \\ Humanidades, Estado e desafios didático-científicos}

Londrina, 27 a 29 de julho de 2016

http://www.pagu.unicamp.br/en/simone-beauvoir-os-feminismos-seculo-Xx-1999-

12Acesso: 08 de Jan. de 2016.

VIÑAO FRAGO, Antônio. Sistemas educativos, culturas escolares y reformas. Madrid: EdicionesMoratas, S.L, 2002 